\title{
Uptake of care and treatment amongst a national cohort of HIV positive infants diagnosed at primary care level, South Africa
}

Elelwani Mathivha ${ }^{1,2}$, Steve Olorunju ${ }^{3}$, Debra Jackson ${ }^{4,5}$, Thu-Ha Dinh ${ }^{6}$, Nicolette du Plessis ${ }^{2}$ and Ameena Goga ${ }^{2,7,8^{*}}$

\begin{abstract}
Background: Loss to follow-up after a positive infant HIV diagnosis negates the potential benefits of robust policies recommending immediate triple antiretroviral therapy initiation in HIV positive infants. Whilst the diagnosis and follow-up of HIV positive infants in urban, specialized settings is easier to institutionalize, there is little information about access to care amongst HIV positive children diagnosed at primary health care clinic level. We sought to understand the characteristics of HIV positive children diagnosed with HIV infection at primary health care level, across all provinces of South Africa, their attendance at study-specific exit interviews and their reported uptake of HIV-related care. The latter could serve as a marker of knowledge, access or disclosure.
\end{abstract}

Methods: Secondary analysis of data gathered about HIV positive children, participating in an HIV-exposed infant national observational cohort study between October 2012 and September 2014, was undertaken. HIV infected children were identified by total nucleic acid polymerase chain reaction using standardized procedures in a nationally accredited central laboratory. Descriptive analyses were conducted on the HIV positive infant population, who were treated as a case series in this analysis. Data from interviews conducted at baseline (six-weeks post-delivery) and on study exit (the first visit following infant HIV positive diagnosis) were analysed.

Results: Of the 2878 HIV exposed infants identified at 6 weeks, 1803 (62.2\%), 1709, 1673, 1660, 1680 and 1794 were see at 3, 6, 9, 12, 15 and 18 months respectively. In total, 101 tested HIV positive (67 at 6 weeks, and 34 postnatally). Most (76\%) HIV positive infants were born to single mothers with a mean age of 26 years and an education level above grade 7 (76\%). Although only $33.7 \%$ of pregnancies were planned, $83 \%$ of mothers reported receiving antiretroviral drugs to prevent MTCT. Of the 44 mothers with a documented recent CD4 cell count, the median was 346.8 cell $/ \mathrm{mm}^{3}$. Four mothers (4.0\%) self-reported having had TB. Only 59 (58.4\%) HIV positive infants returned for an exit interview after their HIV diagnosis; there were no statistically significant differences in baseline characteristics between HIV positive infants who returned for an exit interview and those who did not. Amongst HIV positive infants who returned for an exit interview, only two HIV positive infants (3.4\%) were reportedly receiving triple antiretroviral therapy (ART). If we assume that all HIV positive children who did not return for their exit interview received ART, then ART uptake amongst these HIV positive children $<18$ months would be $43.6 \%$.

(Continued on next page)

\footnotetext{
* Correspondence: Ameena.Goga@mrc.ac.za; ameena.goga@mrc.ac.za

${ }^{2}$ Department of Paediatrics, University of Pretoria, Pretoria 0001, South Africa

${ }^{7}$ Health Systems Research Unit, South African Medical Research Council,

Pretoria 0001, South Africa

Full list of author information is available at the end of the article
}

(c) The Author(s). 2019 Open Access This article is distributed under the terms of the Creative Commons Attribution 4.0 International License (http://creativecommons.org/licenses/by/4.0/), which permits unrestricted use, distribution, and reproduction in any medium, provided you give appropriate credit to the original author(s) and the source, provide a link to the Creative Commons license, and indicate if changes were made. The Creative Commons Public Domain Dedication waiver (http://creativecommons.org/publicdomain/zero/1.0/) applies to the data made available in this article, unless otherwise stated. 
(Continued from previous page)

Conclusions: Early ART uptake amongst children aged 15 months and below was low. This raises questions about timely, early paediatric ART uptake amongst HIV positive children diagnosed in primary health care settings. Qualitative work is needed to understand low and delayed paediatric ART uptake in young children, and more work is needed to measure progress with infant ART initiation at primary care level since 2014.

\section{Introduction}

Although there has been a reduction in new HIV infections amongst children aged $0-14$, at the end of 2016, approximately 2.1 (1.7-2.6) million children were infected with human immunodeficiency virus (HIV); $90 \%$ of them lived in sub-Saharan Africa [1-3]. Although interventions to prevent mother to child transmission of HIV (PMTCT) have successfully reduced new paediatric HIV infections, paediatric HIV has not been eliminated [4]. Without treatment, paediatric HIV is a rapidly progressive disease, with high mortality [5]. Since the introduction of triple antiretroviral therapy (ART), and particularly early ART, infant survival rates have significantly improved $[1,2,5,6]$; however, the proportion of children accessing treatment remains unacceptably low. [6, 7]. Although ART coverage for HIV positive children aged 0-14 years increased globally from $28 \%$ in 2009 to $74 \%$ in 2015, and in South Africa from 29\% in 2010 to $55 \%$ in 2016, ART uptake amongst young children under the age of 2 years is unknown [3, 8, 9]. In resource limited settings, not all HIV exposed children receive timely and appropriate infant HIV diagnostics and referral into care; this compromises early treatment $[1,7]$. In South Africa, task shifting, decentralization of HIV treatment and nurse initiated management of antiretroviral therapy (NIMART) have been implemented to scale-up coverage of HIV care. Data demonstrate that NIMART reduces waiting times, loss to follow-up, transport costs and opportunity costs, provides care closer to patients' homes, and increases retention in care [10-12]. By 2010 management of paediatric HIV infection was included in the South African chart booklet of the Integrated Management of Childhood Illness (IMCI) strategy, and guidelines recommended ART for all HIV positive infants (children less than 1 year); by 2013 ART eligibility criteria expanded to include all HIV positive children under the age of 5 years $[13,14]$.

This paper describes the characteristics of HIV positive children aged 6 weeks to 18 months, spread across geographical settings nationally in South Africa, their attendance at study-specific primary health care clinic exit interviews and their uptake of HIV-related care. This provides a deeper understanding of access to care for HIV positive children attending routine, non-specialised health services.

\section{Methods}

\section{Study design}

Secondary analysis of data from HIV positive infants was undertaken. The data were drawn from a nationally representative prospective observational cohort study of HIV exposed infants (HEI), followed up between October 2012 and September 2014 to establish 18-month mother to child transmission of HIV (MTCT) and HIVfree survival. This cohort was established from a nationally representative survey conducted at 580 primary health care clinics / community health centres across all nine provinces of South Africa to measure MTCT at 48 weeks postpartum. During the survey, multistage probability proportional to size sampling methodology was used to establish a nationally and provincially representative sample. Hospitals were excluded from the sampling frame to reduce the bias posed by sick populations, and because hospitals do not routinely offer immunization; our sample was drawn from 6 week immunization service points, which have $>95 \%$ immunisation coverage. All infants receiving their six-week immunization in selected facilities and their mothers/ caregivers were recruited, either consecutively (in facilities without long immunization queues) or systematically (in facilities with long immunization queues based on desired sample size for the day and number of eligible mother/infant pairs in the queue). Infant dried blood spot samples were collected from all consented infants (and not only from infants brought by self-reported HIV positive mothers or whose mothers received interventions to prevent MTCT) and tested at the National Institute for Communicable Diseases (NICD), National Health Laboratory Services for HIV antibody to ascertain HIV exposure. Antibody positive infants or those born to self-reported HIV positive mothers were tested for HIV infection using total nucleic acid polymerase chain reaction (TNA PCR). A closed cohort of HIV antibody positive infants (HEI) was established, and all HEI were subsquently seen at 3-monthly intervals from three until 18 months. At each study visit, mothers / primary carrgivers were interviewed and HEI were tested for HIV (TNA PCR). As per national policy, the laboratory returned all infant HIV test results to their clinic of origin within 1 month. Routine clinic (not research) nurses were required to return results to mothers/parents, confirm the diagnosis and initiate paediatric ART. As per national policy, all children with confirmed HIV infection were eligible for ART, regardless of their CD4 cell count. Results at the 6 week time point have been reported elsewhere[15-17]. and details about how the HIV infected population differs from the rest of the cohort 
are addressed in the overall 18-month MTCT and HIVfree survival paper, which is currently under review. More information about loss to follow-up in the HIV exposed cohort, from which the HIV infected children came, are provided in the paper by Ngandu et.al. in this series. For this paper, given that confirmation of the infant's HIV status would have been complete within 1 month of the blood-taking visit, we expected that HIV positive infants should have received HIV-related care (including ART) before they were seen at the next visit, which was scheduled 3 months later. The study visit 3 months after an infant HIV positive diagnosis, or as soon as possible to the 3 month post HIV diagnosis time point if the mother could not be contacted at this time point, was the study exit interview for HIV positive infants. This visit aimed to check that the infant was in HIV-related care, as infant HIV diagnosis was the study endpoint.

\section{Study population}

HIV exposed infants enrolled in the follow-up study at 4-8 weeks postpartum, and diagnosed with HIV infection at six-weeks, or at 3, 6, 9, 12 or 15 months were eligible for this analysis. All infant HIV diagnoses were made at primary health care level, as hospitals were excluded from the sampling frame.

\section{Data collection methods}

Maternal and infant baseline information was obtained from the 4-8 week interview. Data on infant birth weight and gestational age was obtained from the infant's Road to Health booklet (RTHB), a patient-held booklet issued at birth to all infants born in South Africa. Questions on infant medication were asked at every interview, specifically about infant antiretroviral drug use. A food and medication diary was issued to all HEI at the enrolment visit to assist with recall about medicine and feeding. This diary allowed the mother/caregiver to keep a daily log of medicine and food ingested. The data collector reviewed and collected the diary during each interview. All study exit interviews were conducted at primary health care clinics / community health centers until January 2014; thereafter a non-health facility follow-up site, based on mother's choice, was allowed. If an HIV positive infant missed the scheduled study exit interview they were invited for interviews at all subsequent time points until they attended the study exit interview, or until the infant reached 18 months, whichever came first. Trained research nurses conducted the study exit interview. All study exit interviews were scheduled to coincide with routine child follow-up visits. For mothers who did not return for study exit interviews, data collectors documented the reason for non-return, where possible. Three attempts (telephone calls on three different occasions) were made to contact each mother to return for a study exit interview. Data collectors searched ART clinic records or registers to ascertain whether children with missed study exit interviews were on ART.

\section{Data analysis}

Data were analysed using STATA version 14. As numbers were small, unweighted descriptive analysis was conducted to explore and understand baseline characteristics of HIV infected infants (at 4-8 weeks postpartum) and uptake of study exit interviews and ART. Chi-square tests were used for categorical variables (Fisher's exact test, if expected cell count $<5$; Cochran-Armitage, for ordinal data with one binary variable) and t-tests or Wilcoxon two-sample test for continuous parametric or non-parametric data, respectively. All $p$-values are 2sided.

\section{Ethics approval and consent to participate}

Ethics approval for this secondary analysis was obtained from the University of Pretoria Ethics Committee. The main study was approved by the South African Medical Research Council Ethics Committee and the Centers for Disease Control and Prevention. All HIV positive infants who were not on ART during the study exit interview were referred to routine services for ART initiation. Although visits were synchronized with routine clinic visits, caregiver-infant pairs received R100 (approximately 8USD) per visit, as an inconvenience allowance to cover their travel and opportunity costs.

\section{Results}

Of the 2878 HIV exposed infants identified at 6 weeks, $1803(62.6 \%)$ were seen at 3 months, 1709, 1673, 1660, 1680 and 1794 were see at 3, 6, 9, 12, 15 and 18 months respectively. In total, 101 tested HIV positive (67 at 6 weeks, and 34 postnatally). HIV positive infants were born at an average gestation of 38 weeks ranging from 24 to 42 weeks with a mean birth weight of $2.8 \mathrm{~kg}$. Of these infants, $18 \%$ were born before 37 weeks gestation and 20/101 (19.8\%) had birth weights less than $2.5 \mathrm{~kg}$. Most of these 101 HIV positive infants were born to single mothers $(76.2 \%)$, with a mean age of 26.7 years, grade 8-12 education (75.2\%) and poor access to basic amenities. Approximately three-quarters $(75.2 \%)$ had access to piped water, $50.5 \%$ had a pit latrine and $79.2 \%$ used electricity as the main source of energy (data not shown). Most caregivers travelled to clinic on foot (57.4\%) with an average travelling time of $27 \mathrm{~min}$ (range $2-120 \mathrm{~min}$ ) (data not shown). Socioeconomic circumstances were suboptimal: $24 \%$ of caregivers reported cutting the size of their meals due to non-availability of food. Only a third (33.7\%) of pregnancies were reported as planned. There was poor integration between mother and infant care and between infant immunisation and HIV care (data 
not shown). Most mothers (74.3\%) reported receiving support (from a health care worker or family member) during pregnancy and delivery (data not shown). Most mothers (62.42\%) were not yet on lifelong ART. Of the 44 mothers who knew their CD4 cell count the median was 346.8 cell/ $\mathrm{mm} 3$. Four of the 101 mothers, (4.0\%) self-reported that they had been diagnosed with TB disease by 6 weeks postpartum.

Of the $101 \mathrm{HIV}$ positive infants we were able to trace $59(57.6 \%)$ to conduct a study exit interview (Table 1 ). Of the HIV positive infants who did not present for study exit interview $(n=42)$, approximately a third $(n=$ 13) died between the 6 and 12- month interview, and the rest were difficult to contact (38\%), refused further follow up (28\%) or had relocated (2\%), data not shown. There were no significant differences between HIV positive infants who presented for a study exit interview and those who did not (Table 1). Of the 59 seen for a study exit interview, only 34 (57.6\%) were seen 3 months after the infant's HIV positive diagnosis. The remainder were difficult to trace, and seen at later time points (Table 2). Amongst the 59 children who attended the study exit interview, $88.1 \%(52 / 59)$ were brought by their mothers. Of the infants not brought by mothers, caregivers reported that mothers were alive but not available on the day of the interview. Prior access to HIV-related care amongst infants attending study exit visits, was non-existent or delayed (Table 2); only two caregivers (3.4\%) reported that their HIV positive child was on ART.

\section{Discussion}

Using data from a nationally representative study to determine MTCT and HIV-free survival at 3, 6, 9, 12, 15 and 18 months, we demonstrate poor uptake of study exit interviews and extremely low ART uptake (3.4\%), despite guidelines recommending ART initiation as soon as possible in HIV positive children $<5$ years. If we hypothesise $100 \%$ ART uptake amongst children who did

Table 1 Univariate analysis of factors associated with returning for a study exit interview amongst HIV positive infants aged 6 weeks till 18 months, South Africa, 2012-2014

\begin{tabular}{|c|c|c|c|c|c|c|c|c|}
\hline \multirow[t]{2}{*}{ Characteristics } & \multirow[t]{2}{*}{ Category } & \multicolumn{3}{|c|}{ Returned for study exit interview $n=59$} & \multicolumn{3}{|c|}{ Did not return for study exit interview $n=42$} & \multirow[t]{2}{*}{$P$} \\
\hline & & Number & Mean/Proportion & $95 \% \mathrm{Cl}$ & Number & Mean/Proportion & $95 \% \mathrm{Cl}$ & \\
\hline Mean Age & & 59 & $26.9 \pm 5.4^{\mathrm{a}}$ & {$[25.6,28.3]$} & 41 & $26.3 \pm 6.7^{\mathrm{a}}$ & {$[24.2,28.4]$} & 0.74 \\
\hline \multirow[t]{2}{*}{ Marital status } & Single & 45 & 76.3 & {$[63.5,85.6]$} & 32 & 76.2 & {$[60.7,86.9]$} & 0.99 \\
\hline & Other & 14 & 23.7 & {$[13.9,35.4]$} & 10 & 23.8 & {$[12.2,37.0]$} & \\
\hline \multirow{2}{*}{$\begin{array}{l}\text { Meal Cut in size due to poor } \\
\text { socio-economic circumstances }\end{array}$} & Yes & 14 & 23.7 & {$[13.1-39.3]$} & 10 & 23.8 & {$[13.1,39.3]$} & 0.99 \\
\hline & No & 45 & 76.3 & {$[63.5,85.6]$} & 32 & 76.2 & {$[60.7,86.9]$} & \\
\hline \multirow[t]{2}{*}{ Maternal Education } & 0 up to Grade 7 & 18 & 30.5 & {$[20.0,43.6]$} & 6 & 14.6 & {$[6.6,29.4]$} & 0.06 \\
\hline & Grade 8 and above & 41 & 79.5 & {$[56.4,80.0]$} & 35 & 85.4 & {$[70.6,93.4]$} & \\
\hline \multirow{2}{*}{$\begin{array}{l}\text { Experienced discrimination } \\
\text { due to HIV status }\end{array}$} & Yes & 8 & 16.3 & {$[8.2,29.8]$} & 3 & 9.4 & {$[2.9,26.1]$} & 0.36 \\
\hline & No & 41 & 83.7 & {$[70.2,91.8]$} & 29 & 90.6 & {$[73.9,97.1]$} & \\
\hline \multirow[t]{2}{*}{ Disclosure to friend or family } & Yes & 41 & 69.5 & {$[57.4,80.0]$} & 28 & 66.7 & {$[50.9,79.4]$} & 0.77 \\
\hline & No/other & 18 & 30.5 & {$[20.0,43.6]$} & 14 & 33.3 & {$[20.6,49.1]$} & \\
\hline \multirow{2}{*}{$\begin{array}{l}\text { Infant hospitalised by } 6 \text { weeks } \\
\text { for } \geq 1 \text { nights }\end{array}$} & Yes & 3 & 5.1 & {$[1.6,14.9]$} & 2 & 4.9 & {$\left[\begin{array}{ll}1.2 & 18.0\end{array}\right]$} & 0.96 \\
\hline & No & 56 & 94.9 & {$[85.1,98.4]$} & 39 & 95.1 & {$[82.0,98.8]$} & \\
\hline \multirow{2}{*}{$\begin{array}{l}\text { Mother hospitalised between } 6 \\
\text { and } 14 \text { weeks for } \geq 1 \text { night }\end{array}$} & Yes & 1 & 2.6 & {$[0.03,17.6]$} & 0 & 0 & - & 0.32 \\
\hline & No & 37 & 97.4 & {$[82.4,99.7]$} & 11 & 100.0 & - & \\
\hline \multirow[t]{2}{*}{ Mother on ART } & Yes & 25 & 51.0 & {$[37,64.9]$} & 13 & 40.6 & {$[24.8,58.6]$} & 0.4 \\
\hline & No & 40 & 49 & {$[35.1,63.0]$} & 19 & 59.4 & {$[41.4,75.2]$} & \\
\hline \multirow{2}{*}{$\begin{array}{l}\text { Infant had difficulty breathing } \\
\text { in last } 2 \text { weeks }\end{array}$} & Yes & 6 & 10.2 & {$[4.6,21.1]$} & 3 & 7.3 & {$[2.3,20.9]$} & 0.62 \\
\hline & No & 53 & 89.8 & {$[78.9,95.4]$} & 38 & 92.7 & {$[79.297 .7]$} & \\
\hline \multirow{2}{*}{$\begin{array}{l}\text { Infant had diarrhoea in last } \\
2 \text { weeks }\end{array}$} & Yes & 1 & 1.7 & {$[0.2,1.1]$} & 3 & 7.3 & {$[2.3,20.8]$} & 0.21 \\
\hline & No & 58 & 98.3 & {$[88.5,99.9]$} & 38 & 92.7 & {$[79.2,97.7]$} & \\
\hline Time travelling to clinic (mins) & & 59 & $27.8 \pm 18.3$ & {$[23.0,32.6]$} & 42 & $25.6 \pm 14.2$ & {$[21.2,30.0]$} & 0.50 \\
\hline Infants birth weight (kg) & & 59 & $2.8 \pm 0.53$ & {$[2.7,3.0]$} & 41 & $2.8 \pm 0.55$ & {$[2.6,3.0]$} & 0.98 \\
\hline Infants gestation at birth & & 43 & $37.9 \pm 2.3$ & {$[37.2,38.6]$} & 28 & $37.9 \pm 3.2$ & {$[36.6,39.1]$} & 0.79 \\
\hline Infants weight at 6 weeks & & 54 & $4.4 \pm 0.76$ & {$[4.21,4.6]$} & 38 & $4.22 \pm 0.9$ & {$[3.9,4.5]$} & 0.20 \\
\hline
\end{tabular}

${ }^{a}$ standard deviation 
Table 2 Timing of infant HIV positive test, timing of study exit interview and access to infant HIV-related care

\begin{tabular}{|c|c|c|c|c|c|}
\hline \multirow[t]{3}{*}{ Timing of study exit interview } & \multicolumn{5}{|c|}{ Infant HIV positive detected at 6-week (4-8 weeks) HIV test $N=67$} \\
\hline & \multirow{2}{*}{$\begin{array}{l}\text { Had a study exit interview, } \\
\text { Number, No, (\%) }\end{array}$} & \multicolumn{4}{|c|}{ Caregiver reported during study exit interview: } \\
\hline & & $\begin{array}{l}\text { Mother interviewed at } \\
\text { study exit }\end{array}$ & $\begin{array}{l}\text { Child referred } \\
\text { into ART }\end{array}$ & $\begin{array}{l}\text { Visited an } \\
\text { ART clinic }\end{array}$ & $\begin{array}{l}\text { Child on } \\
\text { ART }\end{array}$ \\
\hline 3 months & $19(28.3)$ & 15 & 1 & 1 & 1 \\
\hline 6 months & $7(10.4)$ & 7 & 1 & 1 & 1 \\
\hline 9 months & $2(3.0)$ & 2 & 0 & 0 & 0 \\
\hline 12 months & $5(7.5)$ & 5 & 0 & 0 & 0 \\
\hline 15 months & $3(4.5)$ & 2 & 0 & 0 & 0 \\
\hline 18 months & $1(1.5)$ & 1 & 0 & 0 & 0 \\
\hline Total positives at 6 weeks with study exit & $37 / 67(55.2)$ & $32 / 37(86.5 \%)$ & $2 / 37(5.4)$ & $2(5.4)$ & $2(5.4)$ \\
\hline
\end{tabular}

Infant became HIV positive between $>8$ weeks and 19 weeks, detected at 3 month visit $N=18$

Had a study exit interview, No (\%)

$7(38.8)$

0

$1(5.6)$

1 (5.6)

0

$9 / 18(50.0 \%)$
Caregiver reported during study exit interview:

Mother interviewed at Child referred Visited an Child on $\begin{array}{lll}\text { study exit into ART ART clinic ART } & \text { ART }\end{array}$

$\begin{array}{llll}6 & 0 & 0\end{array}$

$\begin{array}{llll}0 & 0 & 0 & 0\end{array}$

$\begin{array}{llll}1 & 0 & 0\end{array}$

$\begin{array}{llll}1 & 0 & 0\end{array}$

0

$8 / 9(88.9 \%)$

Total positives at 3 months with study exit interview

Infant became HIV positive between $>3$ and 6 months, detected at 6 month visit $\mathrm{N}=6$

Had a study exit interview, n Caregiver reported during study exit interview: (\%)

9 months
12 months
15 months
18 months
Total positives at 6 months with study exit
interview

12 months
15 months
18 months
Total positives at 9 months with study exit
interview

18 months

0
$2(33.2)$

$1(16.7)$

$1(16.7)$

$5 / 6(83.3)$

$\begin{array}{llll}\begin{array}{l}\text { Mother interviewed at } \\ \text { study exit }\end{array} & \begin{array}{lll}\text { Child referred } \\ \text { into ART }\end{array} & \begin{array}{l}\text { Visited an } \\ \text { ART clinic }\end{array} & \begin{array}{l}\text { Child on } \\ 2\end{array} \\ 0 & 0 & 0 \\ 1 & 0 & 0 & 0 \\ 1 & 0 & 0 & 0 \\ 1 & 0 & 0 & 0\end{array}$

Infant became HIV positive between $>6$ and 9 months, detected at 9 month visit $N=4$

Had a study exit interview, $n$ Caregiver reported during study exit interview: (\%)

$\begin{array}{llll}\begin{array}{l}\text { Mother interviewed at } \\ \text { study exit }\end{array} & \begin{array}{l}\text { Child referred } \\ \text { into ART }\end{array} & \begin{array}{l}\text { Visited an } \\ \text { ART clinic }\end{array} & \begin{array}{l}\text { Child on } \\ \text { ART }\end{array} \\ 2 & 0 & 0 & 0 \\ 0 & 0 & 0 & 0 \\ 0 & 0 & 0 & 0 \\ 2 / 3(66.7 \%) & 0 & 0 & 0\end{array}$

Infant became HIV positive between $>9$ and 12 months, detected at 12 month visit $\mathrm{N}=4$

Had a study exit interview, n Caregiver reported during study exit interview:

(\%)

Mother interviewed at Child referred Visited an Child on study exit into ART ART clinic ART

$3(75 \%)$

3
0

0
0

0
0

0 
Table 2 Timing of infant HIV positive test, timing of study exit interview and access to infant HIV-related care (Continued)

\begin{tabular}{|c|c|c|c|c|c|}
\hline \multirow{3}{*}{$\begin{array}{l}\text { Total positives at } 12 \text { months with study exit } \\
\text { interview }\end{array}$} & $3 / 4(75 \%)$ & $3 / 3(100 \%)$ & 0 & 0 & 0 \\
\hline & Infant became & \multicolumn{4}{|c|}{$\begin{array}{l}\text { HIV positive between }>12 \text { and } 15 \text { months, detected at } 15 \text { month } \\
\text { visit } N=2\end{array}$} \\
\hline & $\begin{array}{l}\text { Had a study exit interview, } \mathrm{n} \\
(\%)\end{array}$ & $\begin{array}{l}\text { Mother interviewed at } \\
\text { study exit }\end{array}$ & $\begin{array}{l}\text { Child referred } \\
\text { into ART }\end{array}$ & $\begin{array}{l}\text { Visited an } \\
\text { ART clinic }\end{array}$ & $\begin{array}{l}\text { Child on } \\
\text { ART }\end{array}$ \\
\hline $\begin{array}{l}\text { Total positives at } 15 \text { months with study exit } \\
\text { interview at } 18 \text { months }\end{array}$ & $2(100)$ & $2(100 \%)$ & 0 & 0 & 0 \\
\hline TOTAL & $59 / 101(58.4 \%)$ & $52 / 59(88.1 \%)^{a}$ & $2(3.4 \%)$ & $2(3.4 \%)$ & $2(3.4 \%)$ \\
\hline
\end{tabular}

${ }^{a}$ For the 7 infants not brought by mother, mother was alive but not available on day of interview. 67 infections detected at 6 weeks and 34 detected postnatally

not attend the study exit interview paediatric ART uptake would have been $43.6 \%$ (44 children). This uptake is still sub-optimal. Given that we found no significant differences in baseline characteristics between infants who returned for study exit interview and those who did not, we postulate that $100 \%$ ART uptake in the latter group is highly unlikely. Thus, $43.6 \%$ is likely to be an over-estimate of early ART uptake. The poor ART uptake may have been because mothers were waiting for the study nurse to counsel and advise them, or were afraid to take their children to the clinic timeously, or that clinics were still waiting for the confirmatory HIV result, or were still in the process of pre-ART counselling and preparation. Delays in receipt of infant HIV test results have been reported in South Africa, [18]. An observational PMTCT cohort study conducted at Rahima Moosa Mother and Child hospital, Johannesburg between August 2008 and December 2010 demonstrated a median delay interval of 10 weeks recorded between a positive six-week HIV PCR test and initiation of ART with median ART initiation age at 16 weeks of age $[19,20]$. At the time of our study UNAIDS estimated that paediatric ART coverage was $49 \%$ amongst children less than 14 years in South Africa, compared with a more than 90\% ART coverage amongst pregnant women.[4] Our results for children less than 18 months of age are significantly below this modelled national estimate either because the modelled estimate looks at overall access to ART amongst children, and not early access in the first 18 months of life, or due to small numbers of HIV positive children in our study.

Since the discussion of these results at national PMTCT Technical working groups, the National Institute for Communicable Diseases implemented a system that sends out weekly reports to each district, to facilitate tracing of HIV. positive children. The impact of this system remains to be determined.

Our work has several limitations. Although this was a large prospective study drawn from a nationally representative sample of HIV exposed infants, recruited from 580 randomly selected primary health care facilities around South Africa, the number of HIV positive children was small, and analysis did not account for survey design. This, together with the small proportion who returned for study exit interview precluded detailed modelling, and may have biased our assessment of ART uptake. Additionally, all data on ART uptake were selfreported and non-uptake could reflect that the infant was not on ART or that the mother/caregiver did not report that the child was on ART. This is unlikely given the rapport and relationship that developed between mothers and data collectors from recruitment at 6 weeks, and the fact that we used food and medication diaries. We were unable to search laboratory databases to ascertain access to ART or viral suppression, as we did not document infant names in the research database, and had no identifier that linked our study number with a laboratory number. Data collectors had no success finding HIV positive children in clinic ART records/registers. Amongst the HIV positive infants who died, we do not know their ART uptake and response to treatment.

\section{Conclusions}

Our results emphasise the need to strengthen primary health care systems for early paediatric HIV-related care in the first 18 months post-delivery. For policy makers, and at programmatic level, we recommend strengthening outreach systems to find and support HIV positive children and their families[21-23], as poor ART knowledge and false perceptions of high ART costs have been identified as barriers to care and treatment in developing countries $[2,7,10,24]$. Community-level workers could help overcome these barriers. For primary health care facilities, we recommend integrating maternal and child health services to reduce the number of separate visits for each, and investing in regular systematic communitybased tracing of HIV positive children [7, 24]. Further quantitative and qualitative research is needed to understand uptake of paediatric ART and reasons for delayed or poor uptake and adherence.

\section{Abbreviations}

ART: antiretroviral therapy; HEl: HIV exposed infant; HIV: human immunodeficiency virus; IMCI: Integrated Management of Childhood IIIness; 
MTCT: mother-to-child transmission of HIV; NICD: National Institute for Communicable Diseases; NICD: National Institute of Communicable Diseases; NIMART: nurse initiated management of antiretroviral therapy; PCR: polymerase chain reaction; PMTCT: prevention of mother-to-child transmission of HIV; TNA PCR: total nucleic acid polymerase chain reaction

\section{Declarations}

The findings and conclusions in this report are those of the authors and do not necessarily represent the official position of the funding agencies

\section{About this supplement}

This article has been published as part of BMC Infectious Diseases Volume 19 Supplement 1, 2019: Evaluating the effectiveness of national programmes to prevent vertical HIV transmission: Methods, results and implications for PMTCT Option B+ from South Africa. The full contents of the supplement are available online at https://bmcinfectdis.biomedcentral.com/articles/ supplements/volume-19-supplement-1.

\section{Authors' contributions}

Conceptualisation of the paper and providing overall leadership and mentorship for the writing of this paper (AG); Data analysis (AG and SO); writing the first draft of the paper and approving the final version (EM); providing intellectual input to all drafts including the final draft (all authors). All authors read and approved the final manuscript.

\section{Funding}

This paper was supported by the President's Emergency Plan for AIDS Relief (PEPFAR) through the Centers for Disease Control and Prevention, under the terms of Cooperative Agreement Number 1U2GPS001137 and 1U2GGH001150 provided both technical and financial support; UNICEF and the South African National AIDS Council also provided financial support. This work was supported by the South African Medical Research Council (SAMRC). Publication costs were funded by the SAMRC. The views in this paper do not represent those of the funding agencies.

\section{Availability of data and materials}

Data are available from the authors upon request.

\section{Consent for publication}

Consent for publication was obtained from the Centers for Disease Control and Prevention, and from all authors.

\section{Competing interests}

The authors declare that they have no competing interests.

\section{Author details}

${ }^{1}$ Mamelodi Hospital, Pretoria 0112, South Africa. ${ }^{2}$ Department of Paediatrics, University of Pretoria, Pretoria 0001, South Africa. ${ }^{3}$ Biostistics Unit, South African Medical Research Council, Pretoria 0001, South Africa. ${ }^{4}$ Health Section, United Nations Children's Fund (UNICEF), New York, NY 10017, USA. ${ }^{5}$ School of Public Health, University of the Western Cape, Cape Town 7535, South Africa. ${ }^{6}$ Division of Global HIV and Tuberculosis, Center for Global Health, Centers for Disease Control and Prevention, Atlanta, GA 30329, USA. ${ }^{7}$ Health Systems Research Unit, South African Medical Research Council, Pretoria 0001, South Africa. ${ }^{8} 8$ HIV Prevention Research Unit, South African Medical Research Counci, Durban 3630, South Africa.

\section{Published: 16 September 2019}

\section{References}

1. Desmonde S, Essanin J, Aka A, Messou E, Amorissani-Folquet M, Rondeau V. Morbidity and health care resource utilization in HIV infected childrenafter antiretroviral therapy intiation in cote d'Ivoire, 2004-2009. J Acquir Immune Defic Syndr. 2014;65(3):95-103.

2. Auyo P, Musick B, Lui H, Braitstein P, Nyandiko W, Otieno-Nyunya B. Frequency and factors associated with adherence to and completion of combination antiretroviral therapy for prevention of mother to child transmission in western Kenya. J Int AIDS Soc. 2013;16(3):17994.

3. UNAIDS. UNAIDS Data 2017. In: UNAIDS; 2017. Available from http:// aidsdatahub.org/unaids-data-2017-unaids-2017-0. accessed 9 Aug 2018.
4. UNAIDS. Global Plan progress report. 2015. Available from http://www. unaids.org/en/resources/documents/2015/JC2774_2015ProgressReport_ GlobalPlan. Accessed 5 June 2018.

5. Violari A, Cotton M, Gibb D, Babiker A, Steyn J, Madhi S, et al. Early antiretroviral therapy and mortality among HIV-infected infants. N Engl $J$ Med. 2008;359:2233-44.

6. Abrams E, Simonds R, Modi S, Rivadeneira E, Vaz P, Kankasa C, et al. PEPFAR scale-up of paediatric HIV services: innovations, achievements, and challenges. J Acquir Immune Defic Syndr. 2012;60(3):105-12.

7. Braun M, Kabue M, McCollum E, Ahmed S, Kim M, Artker L, et al. Inadequate co ordination of maternal and infant HIV services detrimentally affects early infant diagnosis outcomes in Lilongwe, Malawi. J Acquir Immune Defic Syndr. 2011;56(5):122-8

8. UNICEF. For every child end AIDS: seventh stocktaking report, 2016. Available from https://data.unicef.org/wp-content/uploads/2016/12/HIV-andAIDS-2016-Seventh-Stocktaking-Report.pdf. Accessed 4 June 2018.

9. Nyasulu J, Muchiri E, Mazwi S, Ratshefola M. NIMART rollout to primary healthcare facilities increases access to antiretrovirals in Johannesburg: an interrupted time series analysis. S Afr Med J. 2013;103(4):232-6. https://doi. org/10.7196/SAMJ.6380.

10. Tran D, Shakeshaft A, Ngo A, Rule J, Wilson D, Zhang L, et al. Structural barriers to timely initiation of antiretroviral treatment in Vietnam: findings from six outpatient clinics. PLoS One $2012 ; 7(12):$ e51289; 7(12).

11. Kredo T, Ford N, Adeniyi F, Garner P. Decentralising HIV treatment in lower and middle-income countries (review). Cochrane database of systematic reviews 2013.

12. Emdin C, Milson P. A systematic review evaluating the impact of task shifting on access to antiretroviral therapy in sub-Saharan Africa. Afr Health Sci. 2012;12(3):318-48.

13. National Department of Health and SANAC. Clinical Guidelines: PMTCT (Prevention of Mother-to-Child Transmission). 2010. Available from https:// www.fidssa.co.za/Content/Documents/PMTCT_Guidelines.pdf. Accessed 4 Aug 2019.

14. National Department of Health. The south African antiretroviral treatment guidelines 2013: PMTCT guidelines revised march 2013. Government Printers; 2013. Available from https://www.westerncape.gov.za/assets/ndoh pmtct_guidelines.pdf. Accessed 4 Aug 2019.

15. Goga A, Dinh T, Jackson D, Lombard C, Puren A, Sherman G, et al. Population-level effectiveness of maternal antiretroviral treatment initiation before or during the first trimester and infant antiretroviral prophylaxis on early mother-to-child transmission of HIV, South Africa: implications for eliminating MTCT. J Glob Health. 2016; http://www.jogh.org/documents/ issue201602/jogh-06-020405.pdf.

16. Goga AE, Dinh TH, Jackson DJ, Lombard C, Delaney KP, Puren A, Sherman G, Woldesenbet S, Ramokolo V, Crowley S, Doherty T, Chopra M, Shaffer N, Pillay $Y$ for the South African PMTCT Evaluation (SAPMTCTE) Team. First population-level effectiveness evaluation of a national programme to prevent HIV Transmission from mother to child, South Africa. J Epidemiol Community Health. 2015:69:240-48. doi: https://doi.org/10.1136/jech-2014-2 045352014.

17. Goga A, Jackson D, Lombard C, Ramokolo V, Ngandu N, Sherman G, et al. Highest risk of mother-to-child transmission of HIV or death in the first 6 months postpartum: results from 18 month follow-up of an HIV-exposed national cohort, South Africa - Abstract number: A-792-0314-06477. AIDS 2016. Durban; 2016.

18. Kenny J, Mulenga V, Hoskins S, Scholten F, Gibb D. The needs for HIV treatment and care of children, adolescents, pregnant women and older people in lowincome and middle-income countries. AIDS. 2012;26(Suppl 2):105-16.

19. Lilian R, Kalk E, Bhowan K, Berrie L, Carmona C, Technau K, et al. Early diagnosis of in-utero and intrapartum HIV infection in infants prior to 6 weeks of age. J Clin Microbiol. 2012;50:7.

20. Ghadrshenas A, Amor Y, Chang J, Dale H, Sherman G, Vojnov L, et al. Improved access to early infant diagnosis is a critical part of child centric prevention of mother-to-child transmission agenda. AIDS. 2013;27(Suppl 2):197-205.

21. Sivapalasingam S, Mendillo M, Ahmed A, Mwamzuka M, Said S, Marshed F, et al. The importance of caregivers in the outcome of paediatric HIV management, Mombasa, Kenya. AIDS Care. 2014;26(4):425-33.

22. Lallemant M, Chang S, Cohen R, Pecoul B. Paediatric HIV- a neglected disease? N Engl J Med. 2011;365:581-3.

23. Bhardwaj S, Barron P, Pillay Y, Treger-Slavin L, Robinson P, Goga A, et al. Elimination of mother to child transmission of HIV in South Africa: 
rapid scale-up using quality improvement. . S Afr Med J 2014; 104(3): Suppl1: 239-243.

24. Posse M, Meheus F, Van Asten H, Van Der Ven A, Baltusesen R. Barriers to access to anteretroviral treatment in developing countries: a review. Tropical Med Int Health. 2008;13(7):904-13.

\section{Publisher's Note}

Springer Nature remains neutral with regard to jurisdictional claims in published maps and institutional affiliations.

Ready to submit your research? Choose BMC and benefit from:

- fast, convenient online submission

- thorough peer review by experienced researchers in your field

- rapid publication on acceptance

- support for research data, including large and complex data types

- gold Open Access which fosters wider collaboration and increased citations

- maximum visibility for your research: over $100 \mathrm{M}$ website views per year

At BMC, research is always in progress. 